\title{
Undo Uus
}

\section{SCIENCE AND FOLK} SENTIMENTS

This is a copy of the article from printed version of electronic journal

\section{Folklore Vol. 15}

ISSN 1406-0957

Editors Mare Kõiva \& Andres Kuperjanov

Published by the Folk Belief and Media Group of ELM

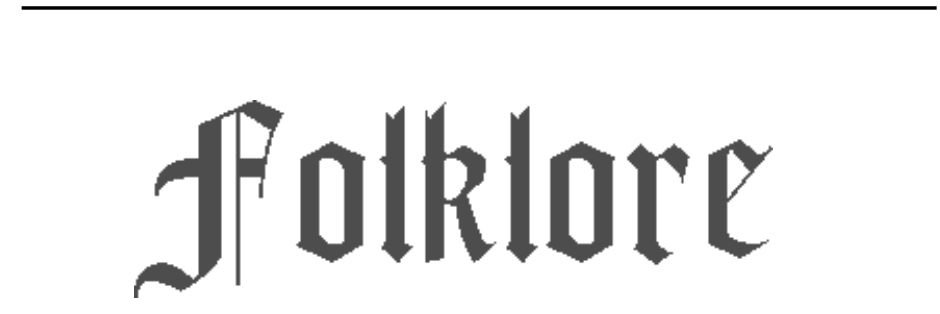

\section{Electronic Journal of Folklore}

Electronic version ISSN 1406-0949 is available from http://haldjas.folklore.eelfolklore

It's free but do give us credit when you cite!

(C) Folk Belief and Media Group of ELM, Andres Kuperjanov

\section{Tartu 2000}




\section{SCIENCE AND FOLK SENTIMENTS}

\section{Undo Uus}

It is generally believed that traditional or commonsense beliefs that contradict scientific views must recede. I will argue that such an opinion is not always justified. In particular, I claim that the modern scientific notion of the fundamental nature of the world and life may very likely prove to be false, whereas some relevant "unscientific" folk sentiments may prove to be essentially correct.

Science and traditional common sense, which both seek truth, are not adversaries. Science can even be regarded as a sophisticated and highly disciplined form of common sense. Therefore it might seem that we should always prefer scientific claims to traditional folk beliefs.

It is undoubtedly true that folk sentiments cannot compete by any means with most of what science tells us. Scientific claims express the results of concerted efforts by large communities of highly educated and trained specialists who use very complicated technical equipment and apply intricate theoretical methodologies. Consider, for example, such fields of research as particle physics, cosmology, or genetics. The world is not, however, a primitive entity and our epistemic situation therein need not be simple. It is for that reason that untutored common sense can in some respects be more rational than science. To understand how this can be so, let us turn our attention to the perils inherent in our scientific pursuit of truth.

It is natural that we wish to ground our beliefs about the world on as firm data as possible. It is also very reasonable that we attempt to avoid any logical inconsistencies inside our belief systems. In these regards the collection of folk sentiments is certainly much inferior to the body of knowledge science advocates. Yet the lack of a clear factual basis and the toleration of inconsistencies may give commonsense reasoning definite advantages over scientific ratiocination. 


\section{THE PERILS OF THE SCIENTIFIC QUEST FOR A FIRM BASIS OF EMPIRICAL KNOWLEDGE}

In general, the desire to found our beliefs upon firm and clear empirical facts is commendable. It is always reasonable to establish, if possible, a solid observational basis for a definite belief rather than to hold to it relying upon vague and ambiguous data. It is therefore understandable that science applies certain strict criteria a fact must satisfy in order to be accepted as a basis for reliable conclusions. However, using of such criteria may prove detrimental to our search for truth. Our world may be - and I will argue that it very likely actually is - of such character that the picture of the world formed on the basis of the most trustworthy empirical data we currently possess is incorrect, and that some very basic properties of the world reveal themselves in the specific kinds of facts which common sense recognizes but science, in its quest for utmost certainty and clarity, rejects.

Science acknowledges as truly scientific only the so-called objective facts, i.e. the facts that are publicly accessible (Hempel 1958). This class of facts consists of data about the formal (abstract) structure and dynamics of the physical world (Carnap 1969). On the basis of these data a conclusion of paramount importance for our understanding of the world has been drawn. In all cases the physical processes have been rigorously investigated, their dynamics have proved lawful, either deterministically or probabilistically, and it has been inductively concluded that the dynamics of the world are thoroughly law-governed. This claim is regarded as the main doctrine of the scientific world-view, and from that it follows that the world is ontologically mundane or, in common parlance, natural. Everything that takes place is determined, in the final reckoning, by the laws of physical dynamics obeyed by the fundamental constituents of matter.

We ourselves are also regarded as thoroughly material (though structurally extremely complicated) beings. In this case our behavior, being determined by our cerebral dynamics, is also entirely lawgoverned, i.e. subject to the combination of rigid determinism and blind (quantum) chance. This in effect means that we are not free in our deeds, that we have never been able to act other than we 
actually did, or, more precisely, we could have behaved otherwise only as a result of some purely random, indeterministic quantum events.

It is doubtful, however, whether this scientific doctrine is correct. It is in direct contradiction with commonsense views. According to folk psychology, we are in command of our voluntary activity. In everyday life people regard themselves and others as creatures with free will who are able to have behaved otherwise than they have in fact chosen to. It is for precisely that reason that people are considered to be morally responsible for their actions. Is such a common belief an "unscientific" superstition without rational basis? No, it is not. Our belief in possessing free will is empirically justified. We are able to clearly discriminate between what happens to us independently of our will (like heart beating, muscle convulsion, sneezing etc.) and what happens due to our own efforts. The empirical information about our possessing free will lies in the specific phenomenal quality of our efforts of will, the quality we call "the feeling of freedom."

Modern science does not acknowledge the feeling of freedom as a scientific empirical fact. First of all, the experiences of efforts of will are the phenomena of consciousness and thus not publicly observable but may be witnessed only privately - introspectively. Science is very reluctant to regard introspection as a genuine scientific observation. Moreover, the information about having free will lies in the phenomenal quality of experiences, but the qualities of this kind - qualia - are, unlike structural information, ineffable and cannot thus be interpersonally communicated.

As concerns access, verifiability and communicability, the facts about qualia are not as "good" as the facts about physical phenomena, and modern science does not recognize them. If they contradict the accepted scientific beliefs, science claims them to be merely deceptive feelings. Is the discarding of the "bad" data reasonable? It is undoubtedly reasonable only if we have "good" data which supply us with the same kind of information but of better quality than the "bad" data. This might be regarded, with reservations, as reasonable also if we were to hold real hope of obtaining the relevant "good" data in the foreseeable future. But this discarding is utterly unreasonable, if the "bad" data provide us with essential informa- 
tion the "good" data cannot do for being unobtainable, either practically or even in principle.

Modern science, in its quest to rely only upon the observational and experimental data of the most simple and clear kind, ignores other kinds of empirical data which can and very probably do contain extremely valuable information that belies some of the main scientific doctrines deduced on the basis of the data science recognizes.

\section{COMMONSENSE REALISM TOWARDS THE EMPIRICAL}

Common sense does not aspire to absolutely clear and firm grounds for its judgments and does not apply stringent - and thus potentially unreasonable - criteria for the acceptance of facts. It recognizes, for example, the feeling of freedom, which accompanies our voluntary activity, as an unquestionable and very important fact about the basic character of our conduct. The advantage of common sense over modern science lies in its greater tolerance of diversity: it does not restrict itself by paying attention only to the "best" kind of data. Moreover, as concerns the specific variety of the data in question - phenomenal experiences - it has no significant disadvantages in comparison with science because introspective observations, unlike physical measurements, cannot be much enhanced by using sophisticated technical equipment. For that reason folk psychology can even today successfully compete with science in offering a sound basis for the beliefs concerning the fundamental character of our nature.

One can, of course, doubt whether it is reasonable to trust the subjective feeling of being a creature possessing free will (and thus not law-governed), as this conflicts with what science asserts. There is, however, additional evidence that folk sentiments about our nature are probably basically correct. This evidence issues from our subjective knowledge of our tendency to seek pleasant and avoid unpleasant experiences.

The qualitative character of our experiences in many cases has a hedonistic dimension by being pleasant or unpleasant to a certain degree. Consider various tastes, smells, sounds, pains etc. It is obvious to common sense $w h y$ we seek pleasant experiences and try 
to avoid unpleasant ones. We try to eradicate pain, for example, because pain has an intrinsically awful character. And it is also obvious to us that the unpleasant intrinsic character of the pain conditions our efforts directed at eradicating pain. But the modern scientific ideology maintains that intrinsic properties cannot have any effect upon what takes place in the world. A property that could have a causal power must be a relational property: a relation between cause and effect. Phenomenal qualia, however, are not the properties causing definite cerebral events necessary for inducing bodily behavior: if this were so, then our consciousness of them would consist in our being aware of the processes they evoke in the brain, but this is clearly not the case. Phenomenal qualia as intrinsic properties are, so to speak, things in themselves with no potency to causally necessitate the occurrence of anything else. On this ground modern science and materialistic philosophy even disclaim the existence of phenomenal qualia. The existence of qualia is denied either explicitly (Dennett 1991), or implicitly (see, e.g. Hardcastle 1996) by assigning to the word 'qualia' a meaning that has nothing to do with phenomenal qualities but refers instead to definite neurodynamical cerebral processes which can, in principle, be described in formal-structural terms and observed publicly.

Folk psychology holds firmly to the realist position regarding sensations. After all, we have the least possible reason to doubt having experiences: they are empirical data we are directly aware of. Common sense, being theoretically unsophisticated, finds no reason to deny that which is empirically given. Modern science and philosophy, in contrast, give much weight to theoretical speculations and hypotheses concerning conceptions of the world in deciding on the nature of the world. And there is very probably something wrong with these theoretical speculations and hypotheses other than the fact that we do not in fact have phenomenal experiences. We can say that one of the advantages of folk thinking over scientific reasoning is its lesser regard for theoretical speculations and greater respect for that which is empirically given.

One might now think that the folk-psychological position that we are able to respond to our experiences in accordance with their qualitative character must, nevertheless, be wrong, because the intrinsic properties of experiences cannot serve as causes of any- 
thing. But folk psychology has a quick answer to this problem. It holds that our reactions to experiences are not necessitated by our experiences, but are caused by our free will. Though experiences themselves cannot, indeed, cause any effects, we, being aware of our experiences and, as free creatures, being able to evoke our behavioral acts without being causally necessitated to do so, can behave, being rational creatures, in accordance with the content of our experiences. That the character of our experiences does not strictly necessitate our behavior is obvious to common sense from the fact that we can, if we wish, behave irrationally, i.e. not in accord with the content of our experiences.

Consequently, the fact that we are able to adequately respond to the qualitative character of our experiences is additional and very firm evidence that we possess free will.

\section{THE DANGERS OF INFATUATION WITH ELEGANT EXPLANATORY SCHEMES}

Yet why does science refuse so obstinately to recognize the intrinsic qualitative properties of experiences? It is indeed utterly counterintuitive to argue that having phenomenal experiences is merely a deceptive illusion. The reason for this is that if science admitted that we have phenomenal experiences, and are able to respond to them adequately by using our free will, it would then also have to admit that the world is at least partly non-natural or supernatural, which means that the world cannot be described on the basis of an elegant and simple model, as science nowadays does.

It is natural that we like beauty and elegance. This is also true of explanatory schemes in science. It is widely believed that a mathematically elegant scientific theory has a better chance of being true than a cumbersome ad hoc theory. This belief is very probably basically correct.

Science, commanding vast intellectual resources, is able to effectively realize its striving towards theoretical elegance. And one of its most general and elegant theoretical constructions is the modern scientific world-view - the materialistic understanding of the world. According to the materialistic image of the world, the world 
is by nature homogeneous and simple. It consists, in final account, of only a few basic physical constituents or fundamental physical fields. (Many physicists even suppose that there may actually be only one such fundamental component.) The behavior of these constituents is causally determined: it obeys the fundamental laws of physical dynamics. The multifarious richness of phenomena in the world - including biological forms of life and social processes - is combinatorial in character: simple constituents of nature can form, being combined in specific intricate ways, various systems of very different properties.

However, it is too optimistic to hope that the basic nature of the world is so simple that we are already able to comprehend it. The world may even be so complicated that it will never be possible to discover its fundamental essence. It is quite probable our understanding of the world represents only particular general features of the world, as they appear to us on the basis of the knowledge of the world that we have hitherto obtained. The world-view must change with our acquisition of new knowledge, and it is therefore unreasonable to demand that it should be elegant at every stage of its development. This applies also to scientific theories of a more limited scope. It is difficult to satisfy the requirement of completeness and elegance during the process of development.

It is difficult to introduce into the modern scientific world-view any essential modifications without marring its elegance. If we wish to admit that the functioning of only definite systems in the world is accompanied by entities - conscious experiences with their intrinsic qualitative properties - which belong to an entirely different category than physical fields, and that the behavior of only definite systems is determined by free will rather than by causal necessity, we must subscribe to a dualistically nonhomogeneous world-view that is aesthetically unpleasing. Nevertheless, such an eclectic world-view is very probably closer to the truth than the elegant materialistic image of the world, for it takes seriously the empirical data to which we have access.

Folk sentiments do not strive to form a complete and elegant system. Ordinary people do not hesitate to admit that only some systems in the world have experiences and possess free will. The absence of a strong craving for elegance is, in some respects, an ad- 
vantage of common sense over scientific thought, for it renders folk belief complexes flexible towards the admission of various very different concepts. Science is more susceptible to a temptation to apply simple and therefore potentially inadequate schemes in describing and explaining non-mundane real phenomena.

\section{QUESTIONABILITY OF THE REQUIREMENT OF INTELLIGIBILITY}

Science requires that the concepts we use to describe reality must be intelligible - fully understandable to a human mind. This demand is natural: our understanding of the world is more profound if we clearly understand what we are discussing when we use definite concepts to describe the world. On the basis of this principle, modern science considers the concepts of qualia and free will to be highly suspect. The phenomenal qualia are ineffable and incommunicable; they can be neither analyzed nor registered. It is impossible to comprehend how there can be a third possibility in dynamics - free-will behavior - in addition to deterministic and probabilistic dynamics, or a combination thereof.

The requirement to use only intelligible concepts in trying to describe the world is, however, unreasonable. This demand would be sensible only if we were certain that the world is so primitive that we can understand clearly everything it contains. But this is not necessarily the case. The world can contain entities and properties which are not mundane and are for us "unintelligible." And, if we are aware of such phenomena, we must not deny their existence merely on the ground that it is difficult to comprehend their essence clearly. Even time is unintelligible in this sense: it is impossible to avoid circularity in explaining the nature of time, its "passing" in the course of which the present "moves" to the past. But this gives us no cause to deny the reality of time. Thus though we cannot explain the nature of the unpleasantness of pain, we are not justified in denying the existence of pain. In the same way that we have the faculty of comprehending directly and intuitively, without any need for further analysis, that there is a time flow, so we also have the faculty for comprehending directly and intuitively the intrinsic qualities of experiences. And we are also justified in trusting 
our intuitive grasping of our freedom of will, notwithstanding that we are unable to analyze what that exactly means. After all, such entities like time, experiential qualities and freedom of will may well be fundamental entities, which are, in principle, unanalyzable, i.e. not reducible to something more fundamental and simple.

Common sense does not require the concepts it recognizes to be intelligible. It trusts intuition. Phenomena that may be grasped directly and intuitively - such as time, experiential qualities and freedom of will - are unquestionably recognized by common sense. Yet common sense tends to acknowledge even phenomena that require subtlety in order to be grasped intuitively. One such phenomenon is our possession of souls.

\section{THE POSSIBLE EXISTENCE OF IMMATERIAL SOULS}

By soul we mean our (possible) immaterial "core." It is difficult to define with precision the basis of the commonsense idea that a person has an immaterial soul. The possession of a soul is not a directly comprehensible intuitive fact. Probably the main reason for introducing the concept of a soul was the opinion that matter itself is lifeless, inert, inactive, and that the source of our activity must be something immaterial. This view is, of course, erroneous: as we know, complicated material systems like robots can be very active. However, when introducing the concept of an immaterial soul as the source of activity, people probably kept in mind the specific character of their own activity: that this is a genuinely freewill activity. And the source of this kind of activity cannot reside in material systems - that truth is also recognized by materialistic philosophy. But there is probably also another vague intuition behind the idea of having a soul: the intuition that one's personal identity can be guaranteed only by one's possessing an immaterial soul.

An elderly man is considered the same person as the young boy he once was. What is the basis of this identity if he as a material creature is now so different from what he was in his youth? Recent philosophical investigations (Parfit 1986) have shown that, indeed, nothing material can guarantee the personal identity through time. This fact is most explicitly demonstrated by the so-called reduplication paradox (see, e.g. Uus 1994): Imagine that your body will be 
decomposed and thereafter reconstituted in two duplicates; which one is then you? Such sophisticated speculations do not lie behind the common sense belief in immaterial souls. Its grounds for adopting this idea are rather indistinct. And this is probably the reason for which the belief in our having immaterial souls has not in modern societies withstood the pressure of the scientific ideology.

\section{FOLK SENTIMENTS DO NOT SUFFER FROM PRESTIGE COMPLEX}

If conscious beings have free will and immaterial souls, then the world is not thoroughly natural. Modern science does not like this possibility. Why? One reason is that the world's turning out to be at least partly supernatural is disadvantageous to aspirations of the intelligibility of the scientific description of the world. I think, however, that there is also another more subjective reason for which science dislikes any kinds of possible supernatural entities and phenomena.

Modern science maintains that all terrestrial phenomena are natural, and that none are supernatural. Science argues that this view should be accepted because we have no evidence casting doubt on it. Is this indeed so? Of course not. The phenomenal qualia do not fit into the causal fabric of a natural world. Our possession of free will is not compatible with our being thoroughly natural creatures. If modern science were ideologically impartial, it would, on the basis of these facts, also be considering the possibility that the world is not entirely natural. But science does not do this. It uses all its power to downplay the importance of data which discredit the doctrine of the naturalness of the world. Science prefers to deny the existence of experiences than to acknowledge that not everything in our world is natural. Modern science strongly dislikes the possibility that the world may prove to be supernatural. One of the reasons for which science has adopted such a stance is its striving for high prestige.

If the world is natural, then everything can, in principle, be fully understood and explained. In such a world science would be an omnipotent intellectual authority. But if definite terrestrial phenomena are supernatural and thus not entirely transparent to a 
human mind, they cannot be fully, if at all, scientifically explained. Scientists are then forced to admit that they are powerless in the face of specific phenomena. They must abandon the image of their potentially omnipotent understanding of the world that they presently enjoy. Abhorrence of the supernatural is a symptom of the prestige complex from which modern science suffers.

Ordinary people do not suffer from such a prestige complex and do not abhor the possibility that some terrestrial phenomena may be supernatural. To the contrary, to many of us the partial supernaturalness of the world is its positive property - such a world is undoubtedly a more interesting place to live in than a thoroughly natural world. Ordinary people are much more tolerant towards various possible ontological essences of the world than is modern science.

The best evidence that people quite easily accept even the view that the world is highly supernatural are widespread religious beliefs in the existence of a very powerful supernatural being - God. And it is highly probable that such a being indeed exists.

\section{THE TRADITIONAL BELIEF IN THE EXISTENCE OF GOD MAY PROVE TRUE}

Modern science, maintaining that the world is natural, is decidedly against the view that God rules the world. And we must agree that traditional arguments supporting religious views - such as the texts of the scriptures, or various myths - are unconvincing indeed. Science suggests that people advanced the idea of God because they were unable to explain in natural terms the presence of life on Earth, and ascribed the creation of life, and subsequently also the creation of the entire world, to a powerful being. This is probably true, but I think people also had another ground for introducing the idea of there being an omnipotent supernatural agent. This idea can namely be regarded as a relatively ordinary hypothesis: people, being introspectively aware that they themselves are free agents of a definite though rather limited creative power, assumed that there might exist a being (or beings) of the same fundamental nature as they themselves - freewill beings capable of creative acts - but immensely more powerful. 
The idea of a superpowerful freewill being is the most outstanding of all ideas people have had or can ever have. This idea is the basis of most systems of religious belief. The belief in God is, or at least has been, also one of the most widespread folk beliefs. Modern science, however, is extremely sceptical of the possibility of the existence of God. Who might prove to be right in this historical confrontation - traditional religious and folk sentiments or the modern doctrines of science? What can we say, on the basis of the presentday level of human knowledge and reasoning, about whether God exists or not?

In trying to answer from the philosophical viewpoint the question of God's possible existence, it is sensible not to regard God as an infinitely powerful freewill being, but rather as animmensely powerful one. First, the idea of an infinitely powerful being is probably self-contradictory, and, secondly, in any practically important sense there is no difference for us whether God is infinitely powerful, or has sufficient immense power. To avoid terminological confusion, let us call the immensely but not infinitely powerful being not God, but Superpowerful Freewill Agent, SFA for short. And let us divide the given problem into two parts: (i) How plausible is the hypothesis that SFAcan exist? and (ii) Do we have any arguments in favor of the fact that SFA actually exists?

Let me begin by emphasizing a fact of which unsophisticated common sense is not aware but which is obvious to a philosophical mind: The hypothesis that a Superpowerful Freewill Agent exists is a rather "mild" further suggestion compared with the acceptance of the view that we ourselves are freewill beings. When we maintain that we have genuine free will incompatible with the thesis that we are thoroughly material law-governed beings, we thereby reject the view that the world is entirely natural. This claim is a very radical qualitative claim, for it asserts that the world is not by nature mundane, but contains something that is, to a certain degree, definitely supernatural. Having accepted this view, the hypothesis that there may exist freewill agents much more powerful than ourselves is merely a quantitative one: we do not introduce any new kind of fundamental properties into the world but only assume that someone can surpass us significantly in respect of some of our own abilities. The suggestion that we are not the most powerful freewill 
beings in the world is much more plausible than the suggestion that we are. We are not the largest, heaviest, "hottest" etc. "things" in the world, so why should we believe that we are the bearers of the greatest amount of supernaturalness in the world?

Given the high plausibility of the hypothesis that there exists a Superpowerful Freewill Agent, there is reason to wonder if we have any evidence that such a being actually exists in our world. One of the basic philosophical claims of modern science is that we do not possess any such evidence, and therefore the hypothesis concerning SFA is purely speculative, without any empirical support. Moreover, as science maintains that we ourselves are purely natural beings, it does not see any reason for considering this hypothesis tenable. And it is, indeed, true that if we consider the data that science recognizes as genuinely scientific - i.e. data about the structure and dynamics of physical reality - there is not as yet the slightest hint of the possible activity of some SFA. All scientific data obtained to date can be explained entirely naturally, and if not yet actually then at least allegedly in principle. Nor has common sense pointed to any facts that could reveal the presence of an SFA in our world.

Common sense has found no evidence of the existence of an SFA because it has sought for it in the wrong place: in the realm of the same kind of phenomena - in the structure and dynamics of the material world - which is also the only field of research of modern natural sciences. Folk imagination has sought for God's existence in possible non-natural events in the physical world, the most drastic of which could be the alleged creation by God of the material world, in the course of which the principle of natural causation, with the corresponding laws of conservation, would have been radically broken. It is very difficult indeed for common sense to see the appearance of the activity of the hypothetical SFA in our world, because this requires sophisticated reasoning. Only modern philosophical discussions have revealed such phenomena as cannot even in principle naturally be explained.

It is obvious that the best evidence for the existence of a Superpowerful Freewill Agent is provided by phenomena that clearly cannot even in principle be explained by natural causes or by actions of human-type freewill agents. Are we aware of any such phenomena? Yes, we definitely are. These phenomena are so common and so 
"close" to us that hardly anyone suspects them to be puzzling. Here I refer to the "evoking" by our brains of our experiences.

The connection between mental processes and phenomenal qualia is contingent: there are no logical or metaphysical reasons for which given brain processes are accompanied by the qualia they in fact are (see Chalmers 1996). It is impossible, for example, to provide any explanation of why definite patterns of neuron firings give rise to the experience of red rather than blue color. In the words of Thomas Huxley, "how it is that anything so remarkable as a state of consciousness comes about as a result of irritating nervous tissue, is just as unaccountable as the appearance of Djin when Aladdin rubbed his lamp." It is evident that non-phenomenal physical entities themselves lack a causal power to evoke the phenomena of consciousness. One might now suppose that mental processes need not have this kind of power, for it is sufficient if there is a law of nature according to which, whenever specific neuronal processes take place, specific phenomena of consciousness also appear. But in that case the causal potency of evoking consciousness must reside in this law itself, which must thus exist over and above the physical world.

A merely abstract law cannot guarantee the appearance of phenomenal experiences in response to mental processes. What we need here is a very real "something" that must have two remarkable properties. First it must have the power of evoking certain phenomena - conscious experiences - without any causal assistance, because mental processes themselves lack such power. Secondly, it must itself select the law of correspondence between mental processes and phenomenal qualia because of the contingent character of such correspondences. Hence this "something" must be a freewill agent. And it is no wonder that we require a freewill agent to establish a connection between physical (mental) processes and phenomenal qualia, because the psychophysical relations of the opposite direction - from qualia to our bodily responses thereto - are effectuated, as I explained above, by us as freewill beings. The freewill agent, which provides us, as well as other living beings, with conscious experiences, must be extremely powerful. This agent must be able to create contemporaneously a large variety of conscious 
experiences according to a definite regular law. Such a being can rightly be called a Superpowerful Freewill Agent.

In summary, we can quite confidently say that we are aware of the phenomena only SFA can produce - these are our experiences. We have a relatively sound basis for insisting that a Superpowerful Freewill Agent truly exists and participates actively in the functioning of the world. In the confrontation between traditional sentiments and modern scientific doctrines on the issue of whether a powerful supernatural being exists, it is therefore highly probable that truth is on the side of traditional beliefs.

\section{SIGNIFICANCE OF TRADITIONAL FOLK SENTIMENTS IN MODERN SCIENTIFIC ERA}

It is usually believed that in our modern scientific era traditional folk beliefs, if they are not in compliance with what science teaches, are anachronisms which should best be abandoned. It may seem that we need to know them, like the philosophical ideas of past times, only in order to possess an overview of how human thought has evolved over the centuries. These old folk sentiments and philosophical ideas are deemed unable to compete with modern scientific views.

It is unquestionably true that the achievements of modern science are tremendous. Due to science-based technology our everyday life is today entirely different from what it once used to be. The huge amount of concrete knowledge about a great variety of natural processes has been obtained, and could only have been obtained, by means of the very intellectually demanding efforts of many generations of scholars. Traditional folk beliefs contribute virtually nothing to the development of modern science, and in many cases these beliefs are unjustified prejudices hampering the dissemination of true knowledge.

However, the opinion that it would have been better for people to abandon all folk beliefs that are in contradiction with modern scientific teachings is deeply erroneous. All of the remarkable achievements of modern science are due to the exploration and exploitation of only one particular kind of phenomena - the physical proc- 
esses of lawfully regular dynamics. The investigation of such phenomena requires the application of only one particular kind of experimental and intellectual methodology. In the wake of immense practical profit due to the application of such methodologies to such processes, unjustified ontological and epistemological generalizations have won scientific approval: that all phenomena in the world are law-governed material processes, and that all processes taking place in the world can be studied by applying the so-called objective scientific research methodology. But it is very likely, as I have attempted to argue in this paper, that the fundamental nature of the world is not so primitive. In order to be able to understand this truth, we must dare to doubt whether the highly prestigious modern scientific world-view is correct. We should also master, at least to a certain degree, definite concepts and ways of reasoning (intellectual activity) not used or even recognized by modern science. And it would also be conducive to our attempts to comprehend the presence of non-natural processes in the world if we have some ideas, albeit rather vague, about possible supernatural phenomena. Knowledge of the history of philosophy and familiarity with presentday philosophical debates is most favorable to this end. But this kind of knowledge is the privilege of a very few. For most people, and for all young people, the only practically available source of unorthodox ideas are "unscientific" folk sentiments, such as beliefs in having (libertarian) free will and an immaterial soul. Modern science attempts to erase such sentiments from the minds of people. The most insidious tactic used to achieve this is to redefine the meanings of ordinary words which have traditionally been used to refer to phenomena science nowadays does not recognize. Thus, for example, by freewill activity modern science usually means the autonomic but entirely deterministic, complicated activity of material systems (such as robots) and biological creatures. That kind of "free will" (Dennett 1984) has nothing to do with the true, incompatibilist, libertarian freedom of will (Van Inwagen 1983). The meanings of crucial words being redefined, people are robbed of language necessary to express "heretical" thoughts. If modern materialistic science were to succeed in eradicating from people's minds the ideas it abhors, humankind would for a long time remain blind to the facts on the basis of which the non-mundane nature of the world is evident. 


\section{CONCLUSION}

Contemporary science can be likened to a totalitarian regime that applies in its judgement doctrines that are highly successful for practical life. . Dissident folk sentiments appear very puny in comparison with the majesty and achievements of the scientific empire. But in the long run the ridiculed dissident ideas may, however, turn up to be right. And, as I have attempted to argue, this is very probably what will happen. It is therefore desirable that traditional folk sentiments, unless they are pure superstition, not die out. As they cannot be explicitly advocated in the present scientific-ideological situation, their implicit propagation under the pretext of teaching the history of folk beliefs should be very much appreciated.

\section{Acknowledgement}

I acknowledge the support of the Estonian Science Foundation (grant 1742).

\section{References}

Carnap, R. 1969.The Logical Structure of the World. Pseudoproblems in Philosophy. Berkeley.

Dennett, D. 1984. Elbow Room. Oxford.

Dennett, D. 1991. Consciousness Explained. Boston.

Hardcastle, V. 1996. Functionalism's response to the problem of absent qualia. Journal of Consciousness Studies 3(4), pp. 357-373.

Hempel, C. G. 1958. Fundamentals of Concept Formation in Empirical Science. Chicago.

Parfit, D. 1986. Reasons and Persons.

Uus, U. 1994.Blindness of Modern Science. Tartu, Estonia.

Van Inwagen, P. 1983. An Essay on Free Will. Oxford. 